\title{
THE PROLAPSED INTERVERTEBRAL DISC
}

\author{
By A. D. LeIGH, M.R.C.P. \\ Registrar, The Maudsley Hospital, One-time First Assistant, Department of Neurology and \\ Psychiatry, The London Hospital
}

Neurology lays many claims to being one of the more precise and scientific branches of medicine but, nevertheless, there have been several neurological conditions almost mediaeval in their conceptions. One of these is a group included under the general heading of the neuritides-namely, sciatic and brachial neuritis and neuralgia. There is now a large body of evidence to show that the humoral, atmospheric, rheumatic, infective and other various etiologies have resolved themselves, on analysis, into problems of anatomy and physics.

Pain in the lower limb roughly corresponding to the course of the sciatic nerve had attracted the attention of clinicians since the work of Contugno in the mid-eighteenth century. Names such as passio ischiadica, sciatic neuralgia, sciatic neuritis, or simply, sciatica, reflect the diversity of etiological theories. As late as 1940 Kinnier Wilson defined sciatica as 'pain confined to the field of the sciatic nerve.' In fact, the pain in sciatica is not related to the field of the sciatic nerve. It is a root pain, with a root distribution.

Out.of the fog of conjecture, it was Déjerine who first suggested that the " sciatic syndrome might be produced by lesions of varying pathology, limited to one or more of the spinal roots emerging from the inter-vertebral foramen.' This suggestion was, unfortunately, almost immediately misinterpreted. There became two types of sciatica - high and low, depending on whether roots or nerve were affected. Terms like radiculitis, funiculitis, trunkitis and plexitis crept into the jargon.

In 1925, however, Schmorl of Dresden, on retirement from active life, had taken up the study of the vertebral column, and was carrying out his painstaking autopsies on the spine. He published his results in 1929, and drew attention to the common occurrence of an prolapse of the nucleus pulposus of the intervertebral disc either into the body of a vertebra,,$\dot{ }$ or posteriorly into the spinal canal. In $3,000 \vec{\omega}$ vertebral columns which he examined a pro $-\frac{9}{0}$ lapse was found in 38 per cent.; in 15 per cent. backwards into the canal ; in 23 per cent. into the vertebral body. Fig. I.

Contemporarily, Elsberg in the States occasionally encountered 'chrondromata' at- $\overrightarrow{-}$ tached to the intervertebral disc, whicho simulated a spinal tumour. He listed $\mathrm{I}_{4}$ in his monograph on ' 100 Spinal Cord Tumours,'? but he did not link up his findings with those of Schmorl-although remarking that histologically the chondroma corresponded to the nucleus pulposus.

It was not until 1934 that Mixter and Bart, at the Massachusets General Hospital, des- $-\frac{\bar{O}}{0}$ cribed 19 cases of compression of the spinalo cord or cauda equina by herniation of the nucleus pulposus through a rupture in the $\overrightarrow{\vec{\sigma}}$ annulus fibrosus. Commenting on this paperGeoffrey Jefferson wrote that 'this new pathological entity deserved widespread: recognition, many cases must miss diagnosis 3 whilst being treated symptomatically as cases:of low backache or sciatica.' These were prophetic words. An intensive surgical attackò on the problem of sciatic pain now began, and $₹$ it is largely to the neurosurgeons that we owe음 the present rational conception of sciatica.

Pain in the shoulder or arm, commonly known as brachial neuritis or neuralgia, has ${ }^{\circ}$ also not escaped the attention of the neuro- $N$ surgeons. Glen Spurling in 1943 recorded $12 \omega$ verified cases of ruptured cervical disc pro 2 ducing pain in shoulder and arm, and more evidence is accruing as to the important role ofo prolapse or a cervical disc in the production of arm and shoulder pain. 


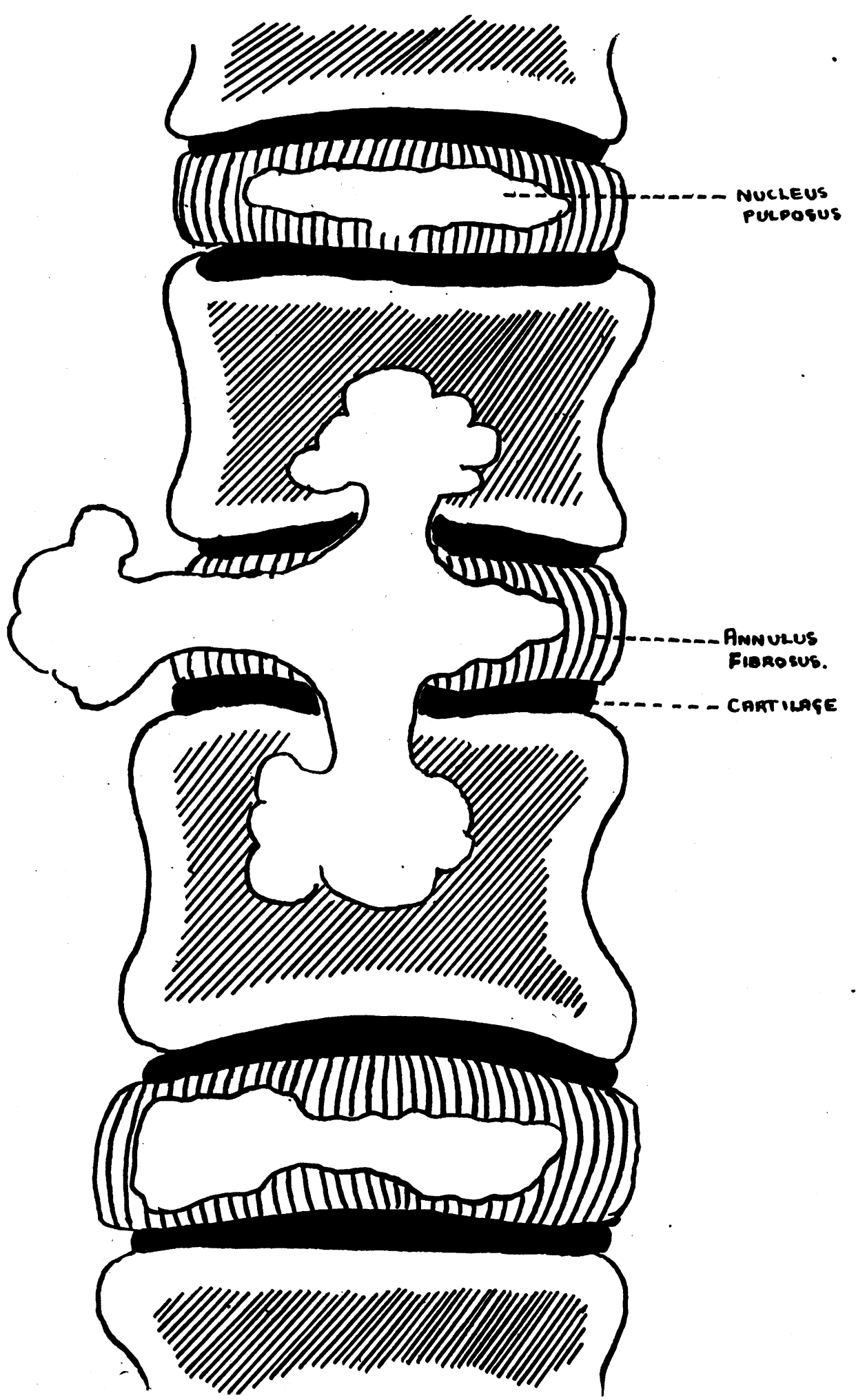

FIG. I. 


\section{The Anatomy and Physiology of the Intervertebral Disc}

The intervertebral discs are tough, fibrocartilaginous structures comprising one quarter of the whole vertebral column. Each is composed at its circumference, of laminae of fibrous tissue and fibrocartilage, stronger anteriorly and laterally than posteriorly-the annulus fibrosus. In the centre is a soft, pulpy, highly elastic substance of yellow colour, which projects above the surface of the cut disc. This pulpy substance, the nucleus pulposus, is particularly well developed in the lumbar region, and contains the remnant of the notochord. The nucleus pulposus receives no nervous supply, but Roofe has shown that there are many nerve endings in the posterior part of the annulus fibrosus and in the posterior longitudinal ligament. These nerve endings he considers to be of the type mediating pain impulses.

The annulus fibrosus behaves as a slightly elastic membrane binding together the vertebral bodies. The nucleus pulposus functions as a shock absorber-physically, it behaves as a fluid and transmits pressure equally over the whole intervertebral surface. When injury to the annulus has allowed the escape of nuclear material, the pressure equalizing system is removed, and the annulus is subjected to stresses with which it is unable to cope. The intervertebral disc may then be ground between the vertebral bodies, and further damage occurs.

The third structure of importance is the ligamentum flavum, which connects the laminae of adjacent vertebrae, and again is particularly thick in the lumbar region. It forms the posterior wall of the intervertebral foramen, and so is intimately related to the emergent nerve root.

\section{Prolapse of the Intervertebral Disc}

True herniation of the nucleus pulposus occurs when the enclosing annulus is ruptured, and a sufficient amount of fibrocartilage escapes through the opening beneath the posterior longitudinal ligament to produce an intraspinal tumour. The rupture may arise suddenly or gradually; it is most commonly situated postero-laterally, the weakest part of the annulus. This rather constant localization of the herniation lies directly beneath the emerging nerve root, and leads to early compression of a single nerve root (Fig. $\stackrel{.}{-}$ 2). In most persons the spinal canal is considerably flattened or narrowed at the lumbosacral junction, which leads to earlier compression here of the nerve root against the overlying ligamentum flavum and lamina. Some, however, have a much larger spinal canal than others, and may have many episodes of low back trouble without definite root? symptoms, as mere displacement of an un- $\vec{\omega}$ restricted, overlaying root is not likely to cause much pain.

The commonest site of herniation is at the lumbo-sacral junction and here both fifth lumbar and first sacral roots are related to the intervertebral disc (Fig. 3). The first saćral root, which is involved in over 50 per cent. of cases, is rather long in its extra-dural course $\stackrel{\circ}{I}$ within the spinal canal, being $4 \mathrm{cms}$. in length. It leaves the main dural canal above the fifth lumbar disc and courses well lateral in the $\frac{\rho}{\mathcal{S}}$ flattened spinal canal of the first sacral regiom $\overrightarrow{0}$ The sensory ganglion of the root lies beneati the first sacral lamina, below the disc, and i hence herniation compresses the nerve roo proximal to the sensory ganglion, and distal to the motor neurones in the spinal cord. This fact is significant-motor regeneration may be expected after a compressive lesion, but sensory regeneration may not occur, as the interruption is a proximal to the ganglion. Another anatomical peculiarity is the absence of trophic changes the roots owing to the fact that there is no overflow of preganglionic sympathetic fibres below L.2.

The first symptom of nerve compression is pain in the hip, which has been called by many names-the superior gluteal nerve syndrome $\frac{}{5}$ (in spite of the fact that this is a purely motor $\frac{7}{0}$ nerve), gluteal myofasciitis, fibrositis, sacro iliac strain, and sciatic neuritis. The factual $\stackrel{\sim}{\sigma}$ explanation is shown in Fig. 2. The posterior N primary division of the root involved comes up $\mathbb{W}^{N}$ against the unyielding ligamentum flavum, producing pain in the distribution of the 0 posterior primary division-which is the $\Phi$ gluteal region. Greater compression of the $\stackrel{?}{?}$ root now involves the central portion, made up of sensory fibres for the anterior primary 
division to the leg, hence the onset now of root pains in the leg. The last portion of the root to be affected is the anterior portion, which is purely motor and produces paresis or paralysis. The great sciatic nerve is formed from five roots $\left(\mathrm{L}_{4}, 5, \mathrm{~S} \mathrm{I}_{1}, 2,3\right)$ and this is the crux of the problem, that the pain in sciatica is a root pain, in the distribution of a root, and not in a nerve distribution.

The great sciatic nerve supplies sensation to a large area below the knee and the pain in sciatica does not correspond to this area (Fig. 4). It is extremely unlikely that a neuritis would select only a portion of the nerve, causing perhaps pain in the buttock, or pain in the back of the thigh or leg. The distribution of the pain, in the classical case, is in the first sacral root area, and this raises some points concerning the anatomy of the five roots involved.

Each of the five roots of the great sciatic nerve represents a segmental motor and sensory pattern which is arranged in serial order, as with the dermatomes of the trunk. The difference is that the extension and rotation of the limb buds, and the fusion of the nerves in the sciatic plexus obscures the order of distribution. We have all been reared on the dermatome charts of Foerster and Head, but recently. Foerster's dictum that division of a single root produces no loss of sensibility has been questioned. Keegan, by careful quantitative testing has been able to map out areas of hypalgesia due to single nerve root compression by a prolapsed disc, proved at operatior. Details may be obtained on reference to his paper, suffice it to say that radicular areas of sensory change are commonly observed in cases of sciatica, particularly in the distribution of the first sacral root.

Sciatica in the Light of these Anatomical Findings

Sciatica may now be defined as pain occurring in the lower limb in a root distribution, resulting from affections of one or more of the five roots which comprise the great sciatic nerve $\left(L_{4}, 5, S_{1}, 2,3\right)$. The commonest cause is prolapse of the nucleus pulposus of an intervertebral disc, usually either the fourth or fifth lumbar disc, affecting the fifth lumbar or first sacral roots, either separately or combined.
There are two components of a typical attack of sciatica, pain in the back and pain in the lower limb of radicular origin.

I. The pain in the back is usually sudden in onset, situated in the lower lumbar region, and associated with stiffness of the lumbar spine. It is well recognized by the laity as ' lumbago.' Trauma or strain determine its origin in approximately 50 per cent. of cases-lifting heavy weights with the back flexed, cranking an obstinate engine, pregnancy or parturition may all precipitate an attack. In the Army the highest incidence was amongst the artillery, particularly the ammunition numbers, and in civil life labourers are frequently affected. However, acute prolapse may be quite unrelated to trauma, and since three-quarters of the cases are past the fourth decade, it seems likely that degenerative processes in the disc have occurred in such patients.

The back pain is severe, unilateral or bilateral, and the patient feels as if gripped in a vice. He may be fixed in an attitude of flexion, and have to be carried to bed, where hot bottles applied to the lumbar region produce time honoured relief. The pain usually pere sists for ten days or longer, and may, or max not, be accompanied by pain in buttock, thigh or leg.

The presence of nerve endings in the annulas fibrosus has already been referred to - the back pain may result from ' irritation' of these nerve endings when the annulus fibrosus is injured.

2. Root pain in buttock, thigh, leg or foot is the second component, and occurs in whichever dermatome area is concerned. A good deal of the confusion of thought concerning sciatica has resulted from the unfortunate coincidence that the course of the sciatic nerve roughly corresponds to the first sacral dermatome.

The pain may be confined to the buttock, or radiate to the posterior aspect of the thigh With the common lumbo-sacral disc herniation affecting the first sacral root, the pain starts in the buttock, spreads down the posterior aspect of the thigh, to the antero-lateral aspect of the leg, and along the outer border of the foot, involving the outer three toes and the outer side of the sole. In character the pain is variously described as 'stabbing,' ' burning,' 


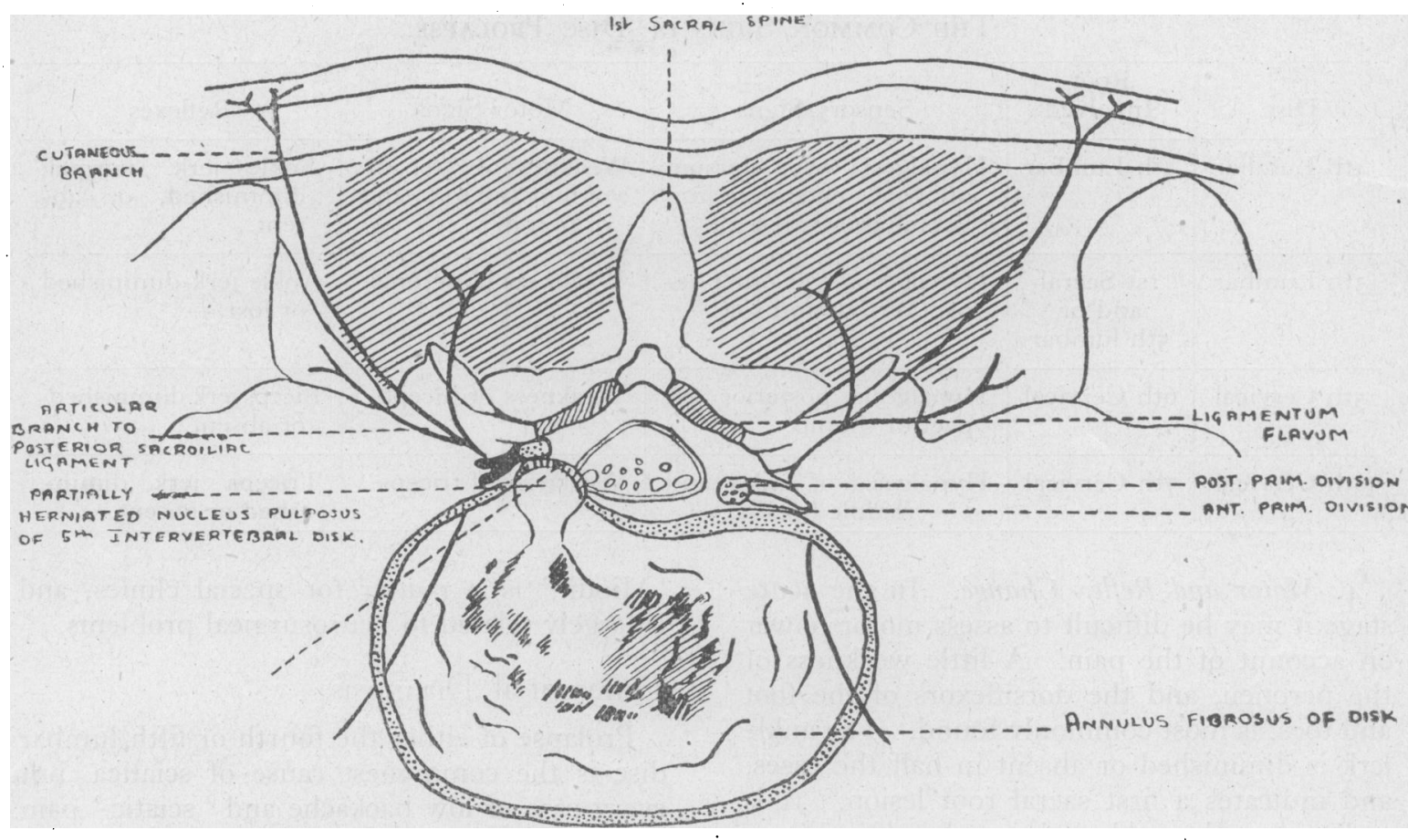

FIG. 2.-(After Keegan.)

' gnawing,' or 'shooting,' and is increased by coughing or sneezing, or by any circumstance which increases the intraspinal pressure. This is the basis of Naffziger's test, on bilateral jugular compression there is an increase in the leg pain. Tingling and numbness along the outer border of the foot commonly occur.

Certain postures aggravate the pain, and a scoliosis is developed to 'protect' the root from pressure.

\section{Physical Signs}

The signs of most diagnostic import are :-

I. A stiff and rigid lumbar spine.

2. A positive Lasègue's sign.

3. Dermatome changes.

4. Motor and reflex change.

I. Loss of the normal lumbar curve, with limitation of forward flexion of the lumbar spine is constantly present. The normal ripple of vertebral movement is lost, and the whole lumbar spine becomes stiff and rigid. This is well demonstrated when the patient attempts to touch his toes, with the knees extended.
2. Straight leg raising is limited in every case-a sign first described by Lasègue in 1864. The sign is positive most commonly on the affected side, but occasionally on the side contralateral to the pain. It is a useful objective indication of the degree of pain, and is helpful in assessing recovery. O'Connell has shown that flexion of the extended lower limb or the thigh stretches the fixed extradural part of the nerve root. This is the portion of the root which is commonly related to the disc protrusion hence the limitation of straight leg raising, known as Lasègue's sign.

3. Dermatome changes. Careful testing by drag pin discloses areas of hypalgesia in as many as 80 per cent. of cases, the commonest site being the outer aspect of the foot, indicating a first sacral root lesion. (Figs. 5 and 6.)

The more severe the degree of root compression, the more extensive will be the area of sensory change. Two or more roots may be affected depending on the site, size, or multiplicity of prolapse. A complete cauda equina syndrome may occur when the prolapse is a large one. 
The Common Signs of Disc Prolapse.

\begin{tabular}{|c|c|c|c|c|}
\hline Disc & $\begin{array}{c}\text { Root } \\
\text { Involved }\end{array}$ & Sensory Signs & Motor Signs & Reflexes \\
\hline $4^{\text {th }}$ Lumbar & $5^{\text {th Lumbar }}$ & $\begin{array}{l}\text { Hypalgesia over dorsum } \\
\text { of foot extending up } \\
\text { lateral aspect of leg. }\end{array}$ & $\begin{array}{l}\text { Weakness of extensors } \\
\text { of foot and toes, and } \\
\text { of peronei. }\end{array}$ & $\begin{array}{l}\text { Ankle jerk normal, } \\
\text { diminished, or ab- } \\
\text { sent. }\end{array}$ \\
\hline $5^{\text {th }}$ Lumbar & $\begin{array}{l}\text { Ist Sacral } \\
\text { and/or } \\
5 \text { th lumbar }\end{array}$ & $\begin{array}{l}\text { Hypalgesia over outer as- } \\
\text { pect of foot and sole. }\end{array}$ & Weakness of peronei. & $\begin{array}{l}\text { Ankle jerk diminished } \\
\text { or lost. }\end{array}$ \\
\hline $5^{\text {th }}$ Cervical & 6th Cervical & $\begin{array}{l}\text { Hypalgesia posterior as- } \\
\text { pect of thumb. }\end{array}$ & Weakness of biceps. & $\begin{array}{l}\text { Biceps jerk diminished } \\
\text { or absent. }\end{array}$ \\
\hline 6th Cervical & 7th Cervical & $\begin{array}{l}\text { Hypalgesia of index and } \\
\text { middle fingers. }\end{array}$ & Weakness of triceps. & $\begin{array}{l}\text { Triceps jerk dimin- } \\
\text { ished or absent. }\end{array}$ \\
\hline
\end{tabular}

4. Motor and Reflex Change. In the acute stage it may be difficult to assess motor power on account of the pain. A little weakness of the peroneii, and the dorsiflexors of the foot and toes, is most commonly found. The ankle jerk is diminished or absent in half the cases, and indicates a first sacral root lesion. It is well to test the ankle jerk in several positions, and to use reinforcement, but it is important to realize that a patient may have severe sciatica with no change in his ankle jerk. A diminished or absent knee jerk occurs with a prolapse of the third lumbar disc, where the fourth lumbar root is affected.

\section{C.S.F.}

Lumbar puncture should not be made a routine procedure, but is of great value when a neoplasm is suspect. The C.S.F. protein may be increased with a prolapsed intervertebral disc, but not to the same degree as with a neurofibroma of a nerve root, the commonest differential problem. A protein of over roo mgms. per cent. is very suggestive of neoplasm.

\section{Radiology}

A roentgram serves mainly to distinguish those causes of radicular pain which produce bony changes. The variation in the size of the disc spaces is'so extreme that narrowing of the lumboscral disc is to be interpreted with extreme caution. Contrast radiography, using
'Miodil,' is a matter for special clinics, and is largely related to neurosurgical problems.

\section{Differential Diagnosis}

Prolapse of either the fourth or fifth lumbar 9 disc is the commonest cause of sciatica, but $\frac{\vec{z}}{3}$ every case of low backache and 'sciatic' pain must not be regarded as due to this one cause. Almost identical symptoms may result frorg $\overrightarrow{0}$ any process producing compression of fourt.$\vec{N}$ lúmbar-third sacral nerve roots. In large series of cases in America a neurofibroma of $\vec{z}$ root, or roots, of the cauda equina, has proved to be the likeliest source of diagnostic error. Dandy missed nine such tumours in $1,100 \stackrel{\AA}{\circ}$ operations for presumed disc prolapse, and of $\overrightarrow{\overrightarrow{0}}$ I 5 cases of tumour of the spinal canal operated on by Love, in 8 the symptoms were considered to be the result of a prolapsed intervertebral disc. The differential diagnosis may thus be extremely difficult. However, with a root neoplasm the course is more likely to be progressive, the neurological signs more widespread, and rigidity of the lumbar spine absent. Examination of the spinal fluid is perhaps the $\frac{9}{5}$ most valuable diagnostic aid, a C.S.F. protein $\frac{7}{0}$ of more than 100 mgms. per cent. usually indicates the presence of a neoplasm.

Radiology will distinguish such causes of $N$ root pain as a primary or secondary vertebral $\underset{W}{\mathbb{W}}$ neoplasm, spinal injury, spondylolisthesis or 0 hypertıophic osteoarthritis. Careful physical

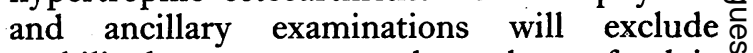
syphilis, herpes zoster, and neoplasm of pelvic $?$ organs. A rectal examination must always be performed. 


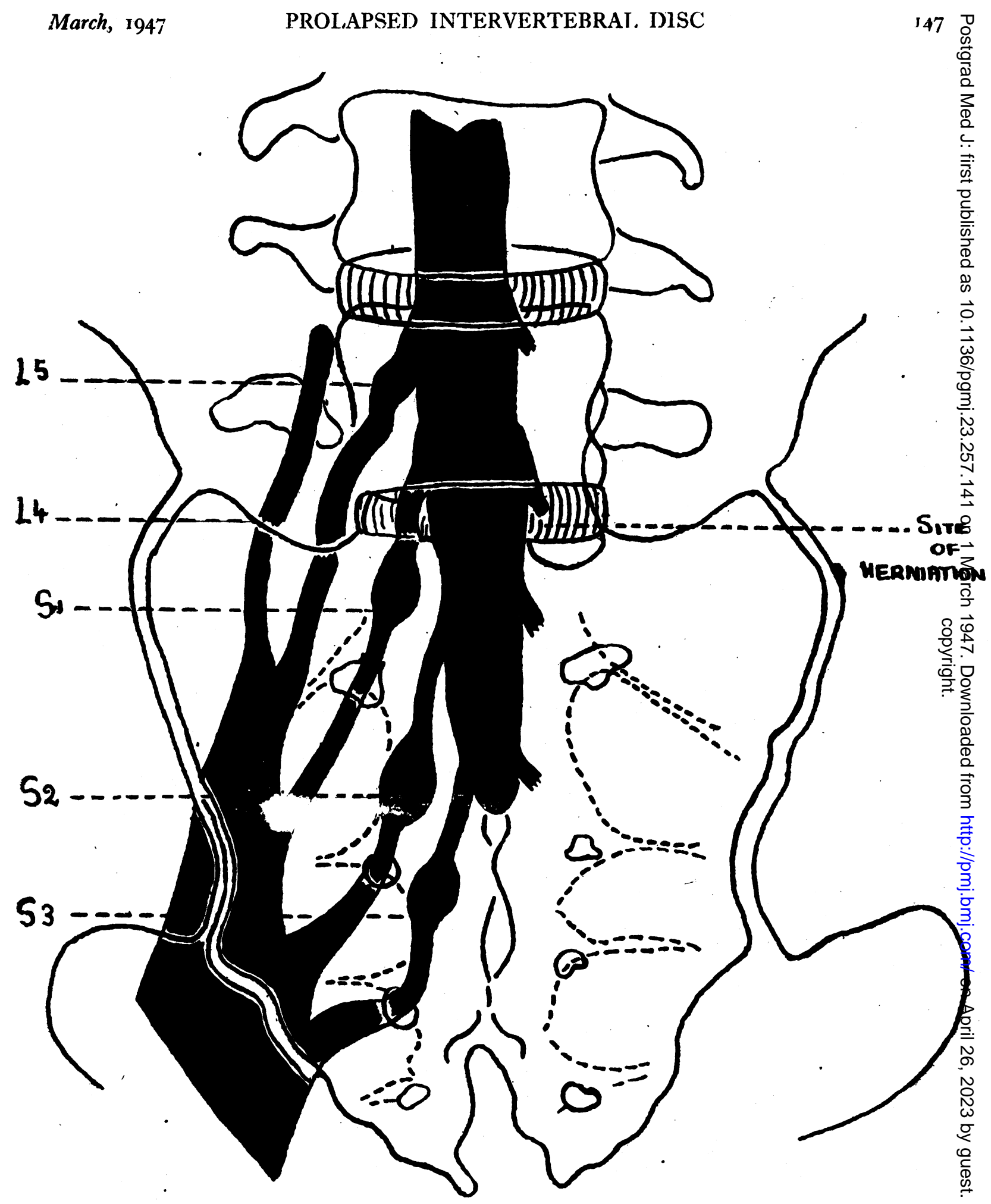

Fig. 3.-Drawing made over roentgenogram to show relation of first sacral and fifth lumbar roots to intervertebral discs. $\frac{D^{\circ}}{0}$ 


\section{BRACHIAL NEURITIS}

Pain occurring at the root of the neck, spreading to the shoulder, arm and hand, for which no organic lesion could be discovered, has been, until recently, as obscure a subject as that of sciatica. 'Rheumatism, chills, wetting, exposure, overstrain and infection' were said to be the more usual antecedents. Happily, however, this 'brachial neuritis' is slowly resolving into several clear cut clinical patterns. One of these is the syndrome of cervical disc prolapse ; in particular, prolapse of the sixth cervical disc.

\section{Anatomy}

There are eight cervical nerves, but owing to the articulation between skull and atlas, only seven cervical intervertebral discs. Thus the first cervical disc is related to the second cervical root, the sixth disc to the seventh root, and so on. The spinal canal in the cervical region is more nearly filled with nervous tissue than the lumbar canal, and the ligamenta denticulata allows only a limited movement of the spinal cord. Hence a prolapse of the nucleus pulposus in the cervical region is more likely to produce early neurological signs than prolapse of a lumbar disc. A central prolapse of a cervical disc produces cord compression, and indeed the earliest reports of cervical disc protrusion are of such lesions (Stookey). When the prolapse is more laterally placed, it projects into the intervertebral foramen producing early compression of the related root.

\section{The Syndrome of Lateral Prolapse of the Sixth Cervical Disc}

Onset of pain and stiffness of the neck is followed by radiation of the pain to the outer aspect of the shoulder and arm, to the posterolateral aspect of the forearm, and into the fingers. Burning, stabbing, or gnawing in quality, there are electric shock like exacerbations of the pain, especially on movement of the neck. Coughing, sneezing or straining causes the pain to shoot down the limb. Paresthesiae in the thumb, index and middle fingers are commonly noted by the patient, and the grip may be weak.

Physical examination discloses evidence of a seventh cervical root lesion. There is weak- ness and wasting of triceps, with some weakness of extension of the wrist and fingers. The triceps jerk is reduced or absent. Sensory diminution to pin prick and cotton wool is found over the index finger; the middle finger and terminal phalanx of the thumb may also be affected. There is limitation of neck movement, and pressure lateral to the sixth cervical spine may produce the characteristic pain.

\section{Radiology}

Narrowing of the disc space is of more significance in the cervical region than in the lumbo-sacral region, and the X-ray may dis-

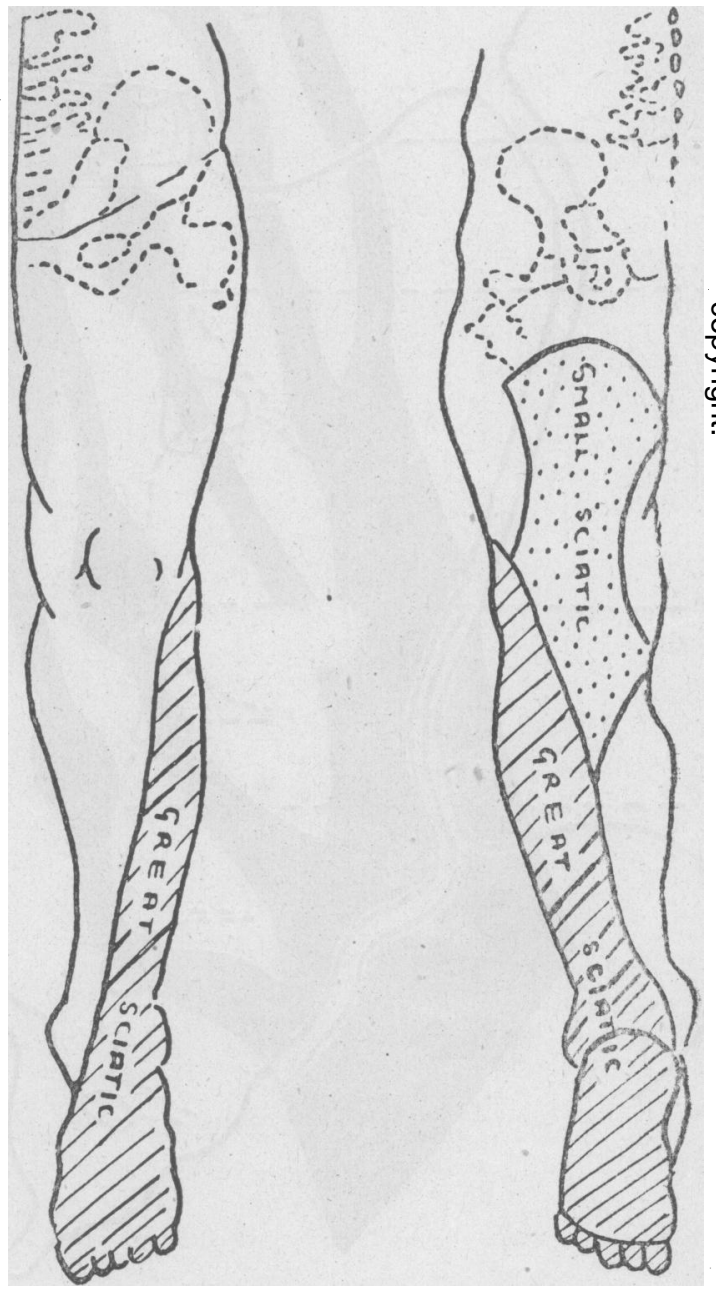

Fig. 4.-Peripheral sensory distribution of the great sciatic and small sciatic nerves. 
close narrowing of the sixth cervical disc, with attempts at bridging between C.6 and C.7.

\section{Differential Diagnosis}

The commonest source of error, as in the diagnosis of sciatica, is a neurofibroma of a cervical nerve root, and again an increase of protein in the C.S.F. is suggestive, although lower figures obtain than with cauda equina neoplasms. A particular variety of neurofibroma may present as a swelling in the neck -the so-called dumb-bell tumour-which grows out of the spinal canal through the intervertebral foramen.

A cervical rib usually produces pain in the fingers or hand, in a first dorsal root distribution. Other causes of brachial plexus compression such as neoplastic invasion, a Pancoast tumour, or infiltration by lymphadeno-
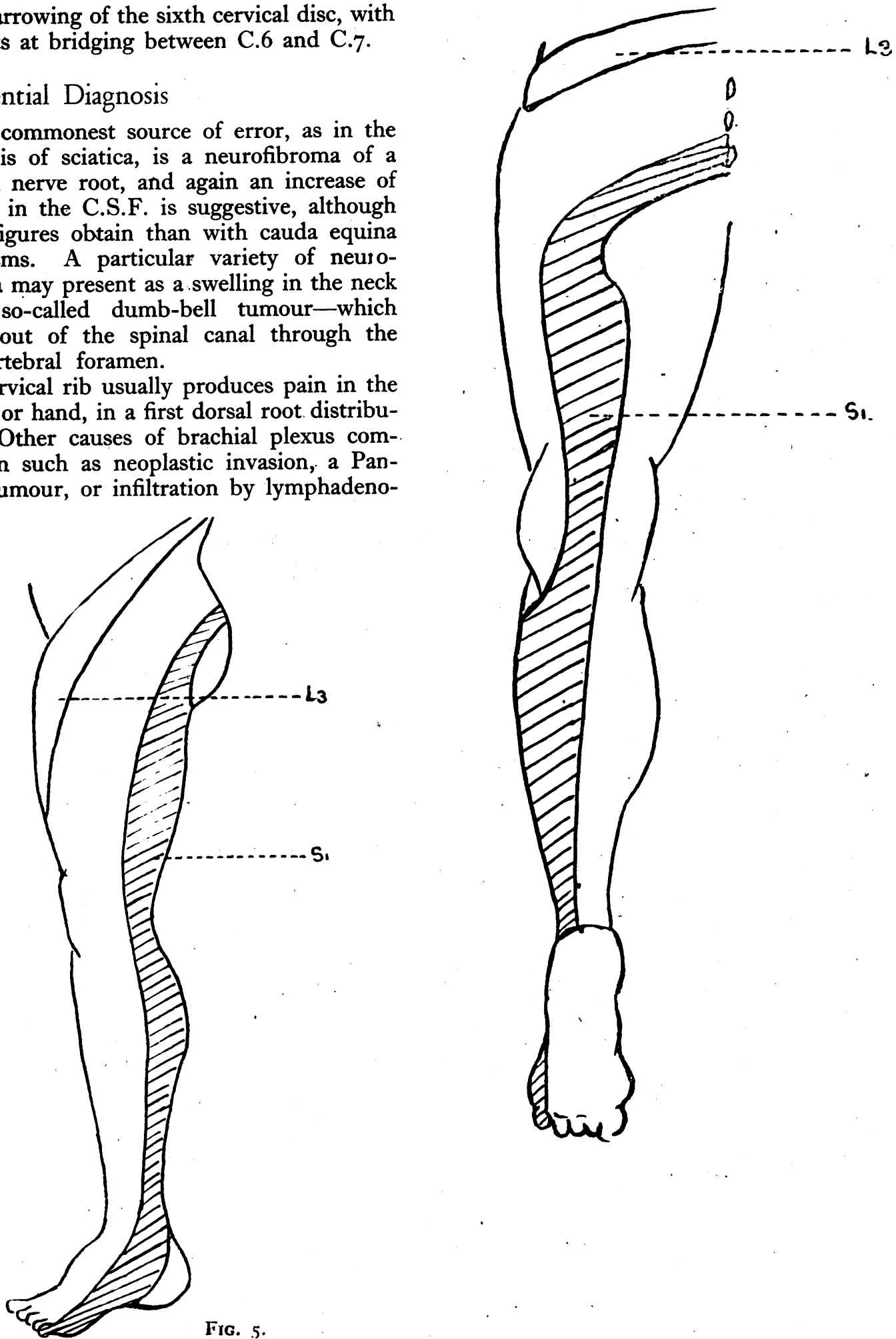

Frg. 5. 
matous tissue are excluded by general examination, as are affections of the head of the humerus or shoulder joint-osteoarthritis; injury or infections.

Angina pectoris, with radiation of pain to the upper limb, is characterized by its relation to effort and is unaccompanied by the physical signs so typical of disc prolapse. Herpes zoster, syphilitic radiculitis, and syringomyelia are mentioned only to be dismissed.

\section{Treatment}

In the past the treatment of sciatica has been as mystical as its etiology was mysterious. Radiant heat, counter irritation, painting the skin over the course of the nerve with fuming hydrochloric acid, infiltration of oxygen around the nerve, epidural injections, and acupuncture were all employed, and still are employed. As recently as I94I Walsh wrote that 'acupuncture of the nerve with a series of specially designed needles is a useful and ancient remedy which acts by puncturing the sheath of the nerve, and allowing the escape of inflammatory exudation.'

On the basis of the anatomical and pathological facts now described, an attempt at treatment along simple, rational lines may be made. The same principles apply to the treatment of both sciatica and those cases of brachial neuritis resulting from disc prolapse. Absolute rest in bed is necessary for a period sufficient to allow healing of the torn fibres of the annulus fibrosus, and at least the inception of cicatrization. For a case of sciatica the following regime is adopted :-

I. Three weeks absolute bed rest, with as low a pillow as is comfortable. The patient is kept prone and is not even allowed to sit up in order to keep the weight of the body off the lumbar discs. Skilled nursing care is essential.

2. At the end of the third week, if there has been subjective improvement, the patient is allowed up to the toilet for the next seven days.
3. In the fifth week he is allowed up for increasing periods each day, until by th $\_$end of the week he is up for the whole day.

4. In the sixth week spinal exercises are given. He is then given a simple explanation of the cause of his sciatica, and advised against lifting heavy weights, playing golf or any procedure likely to cause a further prolapse of his weakened disc. A change of occupation may be essential.

Throughout this tedious and boring period of decubitus, encouragement and reassurance by the doctor plays an important part, and the co-operation of the patient will often depend on the attitude of the doctor.

With the above regime relief occurs in a large number of patients. There is a residuum, however, who do not respond to such measures, and depending on such factors as the constitutional make-up, or on environmental circumstances, operation may be recommended. Large series of laminectomies have been performed, especially in the States. In skilled hands the operation is safe, and the patient is out of hospital in three weekso Opinions still vary, however, as to the place of operation in the treatment of sciatica.

In brachial neuritis resulting from prolapse of a cervical disc, a similar, but less lengthy regime is usually successful. When there is evidence of cord compression, laminectomy must be performed, but it is only rarely necessary with lateral prolapses. Symptomatic therapeusis for relief of pain and sleeplussness is conducted on general principles.

\section{Conclusion}

There are many aspects of both conditions which have not been touched upon in this brief account. The main stream of papers at the moment is devoted to the role of surgery in treatment. For the present, however, the treatment of sciatica and brachial neuritis is still the purlieu of the physicians.

\section{REFERENCES}

r. DANDY, W. E. (1943), Ann. Surg., 4, 639.

2. DEJERINE, J. (I914),' Semiologie des Affections du Systeme Nerveux,'Paris.

3. ELLIOTT, F. A., and KRAMER, M. (1945), Lancet, 4

4. ELSBERG, C. A. (1916), 'Diagnosis and Treatment of Surgical. Disease of the Spinal Cord and Membranes, Philadelphia.

5. GRAY, H. (1930), ' Anatomy of Human Body,' London.

6. JEFFERSON, G.' (I936), 'Medical Annual,' Bristol.
7. KEEGAN, J. (1943), $A . N$. and $P$., 50, 67-83.

8. KINNIER WILSON, S. A. (1940), 'Neurology,' London.

9. MIXTER W. J., and BARR, J. S. (1934), New Eng. F. of Med., $2 \mathrm{II}, 210$.

10. ROOFE P. G. (1940), Arch. N. and P., 44, 100.

11. SCHMORL, G. (1927), "Verhande d. deutschen Orthop. Gesellsch, 21, 3. R., and BRADFORD, F. K. (1941), 'The
SPURLING, G. Intervertebral Disc,' Springfield. 